\title{
Utilização de Geotecnologia para o Mapeamento de Áreas de Preservação Permanente no Município de João Neiva, ES
}

\author{
Alixandre Sanquetta Laporti Luppi ${ }^{1}$, Alexandre Rosa dos Santos ${ }^{1}$, \\ Fernando Coelho Eugenio ${ }^{1}$, Lorena Sant' Anna Feitosa ${ }^{1}$ \\ ${ }^{1}$ Centro de Ciências Agrárias - CCA, Universidade Federal do Espírito Santo - UFES, Alegre/ES, Brasil
}

\begin{abstract}
RESUMO
Este estudo propõe-se a demonstrar como a utilização de geotecnologias pode ajudar de forma eficaz no mapeamento de Áreas de Preservação Permanente (APPs), auxiliando no entendimento das áreas a serem preservadas. O estudo foi realizado em todo o município de João Neiva, ES, com o objetivo de elaborar mapas analógicos e digitais do município; delimitar as Áreas de Preservação Permanente na óptica da Legislação Ambiental; confrontar essas áreas com o uso da terra correspondente; e ressaltar a importância de identificar as áreas de forma automática, para que se possam implantar projetos ambientais que visem promover ações em busca de um relacionamento sustentável entre homem e ambiente de forma mais eficiente. O município de João Neiva possui uma área de $88,64 \mathrm{~km}^{2}$ de APPs totais (32,55\% da área total do município). As APPs ao redor de nascentes (buffer de $50 \mathrm{~m}$ ), nas encostas com declividade superior a 45 graus, topos de morro (terço superior de morros) e margens dos cursos d'água (buffer de $30 \mathrm{~m}$ ) representaram, respectivamente, $0,54 \mathrm{~km}^{2}(0,20 \%), 1,92 \mathrm{~km}^{2}(0,70 \%), 62,66 \mathrm{~km}^{2}(23,01 \%)$ e $23,50 \mathrm{~km}^{2}(8,63 \%)$ da área total do município.
\end{abstract}

Palavras-chave: APPs, sistemas de informações geográficas, legislação ambiental.

\section{Utilization of Geotechnology for the Mapping of Permanent Preservation Areas in João Neiva, Espirito Santo State, Brazil}

\begin{abstract}
This study intended to demonstrate how the use of Geotechnology can effectively help to map Permanent Preservation Areas (PPA), aiding in the understanding of the areas to be preserved. The study was conducted in the total area of the municipal district of João Neiva, Espirito Santo state, aiming to elaborate analogical and digital maps of the municipality; delimit the PPAs from the perspective of the Environmental Legislation; confront these areas with the corresponding land use; and emphasize the importance of identifying the areas in an automatic way, so that environmental projects that seek the promotion of actions in search of an efficient, sustainable relationship between humans and the environment can be implemented. The municipal district of João Neiva comprises a total PPA area of $88.64 \mathrm{~km}^{2}$ (32.55\% of its total area). PPAs around water springs (buffer of $50 \mathrm{~m}$ ), on the hillsides with slope greater than 45 degrees, on hill top (upper third of hills), and along the margins of water courses (buffer of $30 \mathrm{~m}$ ), represented, respectively, $0.54 \mathrm{~km}^{2}(0.20 \%), 1.92 \mathrm{~km}^{2}(0.70 \%), 62.66 \mathrm{~km}^{2}(23.01 \%)$ and $23.50 \mathrm{~km}^{2}(8.63 \%)$ of the total area of the municipal district.
\end{abstract}

Keywords: PPAs, geographic information systems, environmental legislation. 


\section{INTRODUÇÃO}

Os problemas relacionados ao ambiente e seu futuro vêm sendo abordados constantemente, visando à necessidade de se preservarem os recursos naturais como um todo, pois esses são as riquezas básicas de uma nação e não se pode compreender que o desenvolvimento e progresso dela sejam obtidos à custa da dilapidação ou do mau uso deles (Bertoni \& Lombardi Neto, 2008 apud Louzada, 2008).

As Áreas de Preservação Permanentes (APPs) atualmente estão submetidas a grandes extensões de degradação, devido à intensificação das pressões antrópicas sobre o ambiente. Dessa forma, observa-se um processo de substituição das paisagens naturais por outros usos e ocupações da terra e a conversão das áreas com cobertura florestal em fragmentos florestais, causando problemas ambientais e, em muitos casos, afetando a disponibilidade de recursos naturais importantes à vida (Espirito Santo, 2006).

O Novo Código Florestal Brasileiro (Brasil, 2012) relata que as APPs são fundamentais para a manutenção da vegetação de determinadas áreas, com o objetivo de manter inalterado o uso da terra, que deve estar coberta pela vegetação original. Devido às dimensões continentais de alguns países, torna-se indispensável a representação e caracterização das APPs em mapas, importantes para o planejamento territorial, fiscalização e ações de campo de âmbito local, regional ou nacional.

Embora o Brasil possua uma legislação ambiental considerada por muitos como a melhor do mundo, a mesma é deficiente em sua implementação, devido principalmente à grande extensão territorial brasileira, o que na prática a torna uma legislação lenta e pouco eficaz. Um dos fatores que contribui para torná-la pouco ágil é a deficiência em investimentos que visem apurar as agressões cometidas nas áreas primordiais para a manutenção do meio.

As metodologias que utilizam a geotecnologia como ferramenta principal vêm se destacando, sendo a alternativa mais viável para se reduzir significativamente o tempo gasto com o mapeamento das áreas a serem protegidas, e, por consequência, agilizar o período hábil de fiscalização no cumprimento das leis pertinentes.

Um dos impecilhos para o monitoramento das APPs é técnico, pois se faz necessário o envolvimento de profissionais especializados e o uso de dados altamente precisos da área de estudo. Tais dados geralmente são disponibilizados em uma escala muito pequena, e, por consequência, possuem pouca riqueza de detalhes. Contudo, a utilização de equipamentos e o desenvolvimento de sofisticados algoritmos e a sua incorporação ao conjunto de funções das geotecnologias permite o processamento rápido e eficiente dos dados necessários para a caracterização das variáveis morfométricas do terreno (Oliveira, 2002).

A geotecnologia adequa-se perfeitamente à abordagem territorial na medida em que permite a distribuição espacial dos dados, a visualização das relações espaciais, a detecção de processos de concentração e de dispersão de fluxos e contrafluxos, bem como a identificação dos processos históricos de comportamento dos dados (Pina, 2009 apud Louzada et al., 2009a).

Nesse contexto, o presente trabalho propôs demonstrar como a geotecnologia pode ajudar nos estudos das Áreas de Preservação Permanente no que se refere a sua identificação e delimitação automática, o que auxiliará, no futuro, o entendimento dos processos de ocupação da terra.

Sendo assim, o objetivo principal deste trabalho foi delimitar as Áreas de Preservação Permanente do município (faixas marginais, topos de morro, nascentes e encostas), na óptica da Legislação Ambiental, e confrontar o seu uso com o determinado.

\section{MATERIAL E MÉTODOS}

\subsection{Aspectos físicos da área de estudo}

A área de estudo é o município de João Neiva, localizado na Microrregião Metropolitana Expandida Norte, na região central do estado do Espírito Santo, Brasil, localizado entre as latitudes $19^{\circ} 37^{\prime} 20^{\prime \prime}$ e $19^{\circ} 47^{\prime} 57^{\prime \prime}$ Sul e entre as longitudes $40^{\circ} 31^{\prime} 37^{\prime \prime}$ e $40^{\circ} 20^{\prime} 28^{\prime \prime}$ Oeste de Greewinch, com área de 272,30 km² (Figura 1).

O clima da região, segundo a classificação de Köppen, é Cwa, caracterizado por inverno seco e verão chuvoso. De maneira geral, a topografia possui relevo bastante acidentado. Basicamente, estão estabelecidas na área culturas de subsistência, café e, predominantemente, pastagens, além dos remanescentes florestais nativos localizados principalmente no topo dos morros. 
LOCALIZAÇÃo GEOGRÁFICA DO MUNICÍPIO DE JOÃO NEIVA, ES.

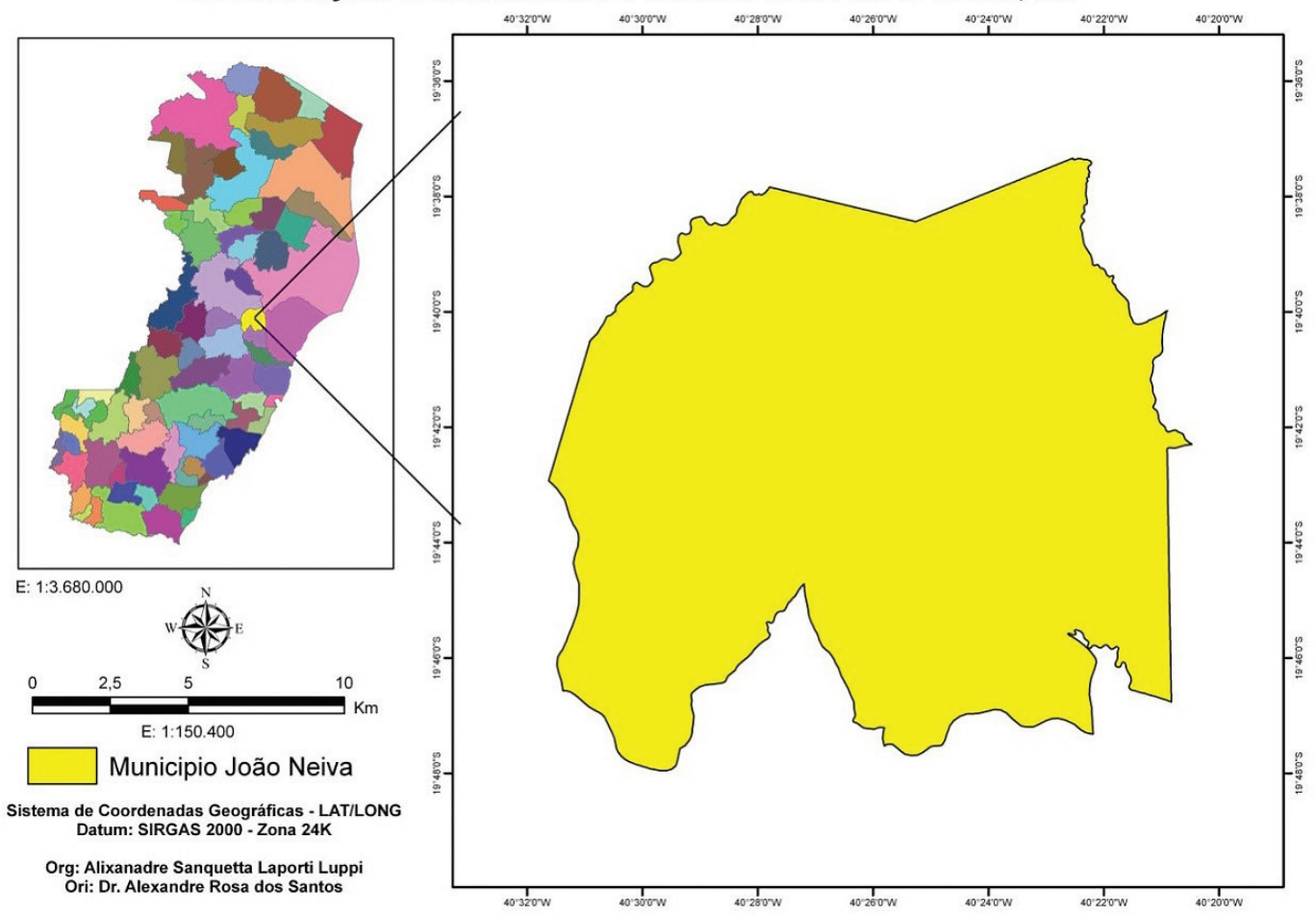

Figura 1. Localização da área de estudo, município de João Neiva, ES.

Figure 1. Location of the study area, municipal district of João Neiva, ES.

\subsection{Desenvolvimento do Modelo Digital de Elevação Hidrologicamente Consistente}

Os dados utilizados para geração do Modelo Digital de Elevação Hidrologicamente Consistente (MDEHC) foram as curvas de nível e a rede hidrográfica, ambos na escala 1:35.000, adotando-se a exatidão cartográfica de 0,143 mm. Assim, para determinar a menor dimensão no terreno representado no mapa, ou seja, a resolução espacial das células do MDEHC, multiplicou-se a exatidão cartográfica pelo fator de escala, que correspondeu a cinco metros.

Determinada a dimensão da célula de saída e de posse dos referidos dados, a geração do MDEHC para o município de João Neiva foi realizada utilizando-se o algoritmo de interpolação "topo to raster", disponível no módulo Arc Toolbox do programa ArcGIS 9.3. As operações necessárias para geração do MDEHC por meio desse algoritmo exigiram a orientação dos arcos da rede hidrográfica no sentido do escoamento e o ajuste da altimetria à hidrografia.
Em seguida foram realizadas operações de pósprocessamento, com a finalidade de identificar e eliminar a ocorrência de imperfeições (depressões espúrias) no MDEHC e para a criação de uma calha ao longo da rede hidrográfica, objetivando garantir a convergência do escoamento superficial até a foz da hidrografia. De acordo com Tribe (1992) e García \& Camarasa (1999), essas imperfeições são muito frequentes nos MDEs, derivando de erros presentes nos dados de entrada ou introduzidos no processo de interpolação. As falsas depressões constituem um problema na geração de modelos de predição do escoamento, pois interrompem o escoamento superficial. Devem, portanto, ser removidas para se ter um MDE consistente sob o ponto de vista hidrológico. Para o preenchimento dessas imperfeições utilizou-se o comando "fill", disponível no módulo Arc Toolbox do programa ArcGIS 9.3.

\subsection{Delimitação das APPs}

De posse dos processamentos realizados nas etapas anteriores, iniciou-se o mapeamento das APPs da área de estudo, considerando-se a faixa marginal dos 
rios, ao redor das nascentes, nos topos de morros e montanhas (terço superior) e encostas com declividades acima de 45 graus, conforme critérios estabelecidos pela legislação, Resolução do Conama n. 303/2002, a qual dispõe sobre parâmetros, definições e limites das APPs (Brasil, 2002).

\subsubsection{Delimitação das APPs ao redor das nascentes}

Nessa etapa foram utilizadas as bases de dados correspondentes ao MDEHC, aos pontos relacionados às nascentes (início de cada córrego) e à rede hidrográfica orientada no sentido da foz. A delimitação das áreas de preservação no entorno das nascentes foi realizada por meio do comando "buffer", disponível no módulo Arc Toolbox do programa ArcGIS 9.3, delimitandose um raio de preservação de 50 metros no entorno das nascentes.

\subsubsection{Delimitação das APPs em topos de morro}

De acordo com a mesma resolução, quando há ocorrência de dois ou mais morros ou montanhas cujos cumes estejam separados por distância inferior a 500 metros, a APP deve abrange o conjunto de morros ou montanhas, delimitado a partir da curva de nível correspondente a dois terços da altura em relação à base do morro ou montanha do conjunto de menor altura. Foi utilizada a metodologia de Hott et al. (2004), da Embrapa, baseada em geotecnologia, aplicando-se rigorosamente a legislação e adotando-se critério na delimitação das elevações por meio do fluxo numérico presente na superfície modelada digitalmente. As etapas necessárias para a elaboração das APPs de topos de morro são mostradas na Figura 2.

\subsubsection{Delimitação das APPs ao longo dos cursos d'água}

Nessa etapa foi utilizada a base de dados correspondente aos cursos d'água, os quais foram fotointerpretados em tela na escala de visualização de 1:2.000, sobre aerofotos ortorretificadas do ano de 2007, com escala de 1:35.000 e $1 \mathrm{~m}$ de resolução espacial, cedidas pelo Iema (Instituto Estadual de Meio Ambiente e Recursos Hídricos). A delimitação das áreas de preservação ao longo dos cursos d'água foi realizada por meio do comando "buffer", disponível no módulo Arc Toolbox do programa ArcGIS 9.3, delimitando-se uma área de preservação de $30 \mathrm{~m}$ em cursos d'água com menos de $10 \mathrm{~m}$ de largura.

\subsubsection{Delimitação das APPs em encostas com declividades acima de $45^{\circ}$}

Nessa etapa, de posse do MDEHC, foi inicialmente elaborado o mapa matricial de declividade da área de estudo utilizando-se o comando "slope", disponível no módulo Arc Toolbox do programa ArcGIS 9.3. Posteriormente realizou-se a reclassificação do mapa

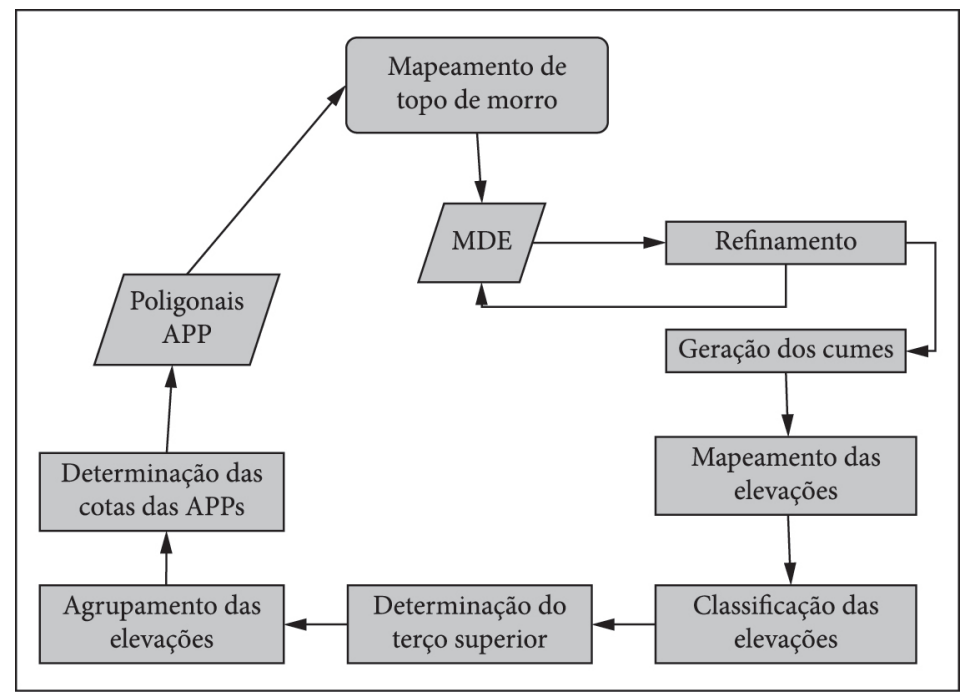

Figura 2. Fluxograma das etapas desenvolvidas na determinação de APPs de topos de morro. Fonte: Louzada et al. (2009b).

Figure 2. Flowchart of the stages developed in the determination of APPs of hill top. Source: Louzada et al. (2009b). 
de declividade com o objetivo de delimitar apenas a classe de APP superior a $45^{\circ}$.

\subsection{Conflito do uso da terra com as APPs}

Utilizou-se a base de dados de uso da terra, os quais foram fotointerpretados na escala de 1:35.000; eles foram recortados sobre as APPs totais (máscara de corte), utilizando-se o comando "clip", disponível no módulo Arc Toolbox do programa ArcGIS 9.3, delimitando-se o uso da terra no interior das áreas de APPs.

\section{RESULTADOS E DISCUSSÃO}

As áreas do entorno das nascentes apresentam suma importância no que diz respeito à vida útil dos rios por elas abastecidos, uma vez que sem a proteção adequada em torno delas nota-se um processo de degradação do rio por ela abastecido, o que fora verificado em visitas técnicas na área de estudo, indo ao encontro do verificado por Donadio et al. (2005), os quais estudaram quatro nascentes, sendo duas com a presença de vegetação natural remanescente e duas com predominância de atividades agrícolas, tendo eles concluído que a presença de remanescentes de vegetação de mata ciliar auxilia na proteção dos recursos hídricos.

A área ocupada por APPs de nascentes é de $0,54 \mathrm{~km}^{2}$, o que representa $0,20 \%$ da área total do município. As delimitações dessas áreas são mostradas na Figura 3.

Devido à natureza do relevo, no município de João Neiva predominam os rios de planalto, que apresentam rupturas de declive, vales encaixados, entre outras características que lhes conferem um alto potencial para a geração de energia elétrica. Em decorrência de seu perfil não regularizado, são rios prejudicados no que diz respeito à navegabilidade, sendo em parte integrantes da bacia hidrográfica dos rios Ubás e Pau Gigante, classificados como dendríticos, típicos de áreas cobertas por rochas sedimentares horizontais.

As APPs de curso d’água garantem a estabilização das margens, tendo assim uma importância vital no controle da erosão do solo e da qualidade da água, evitando o carreamento direto para o ambiente aquático de

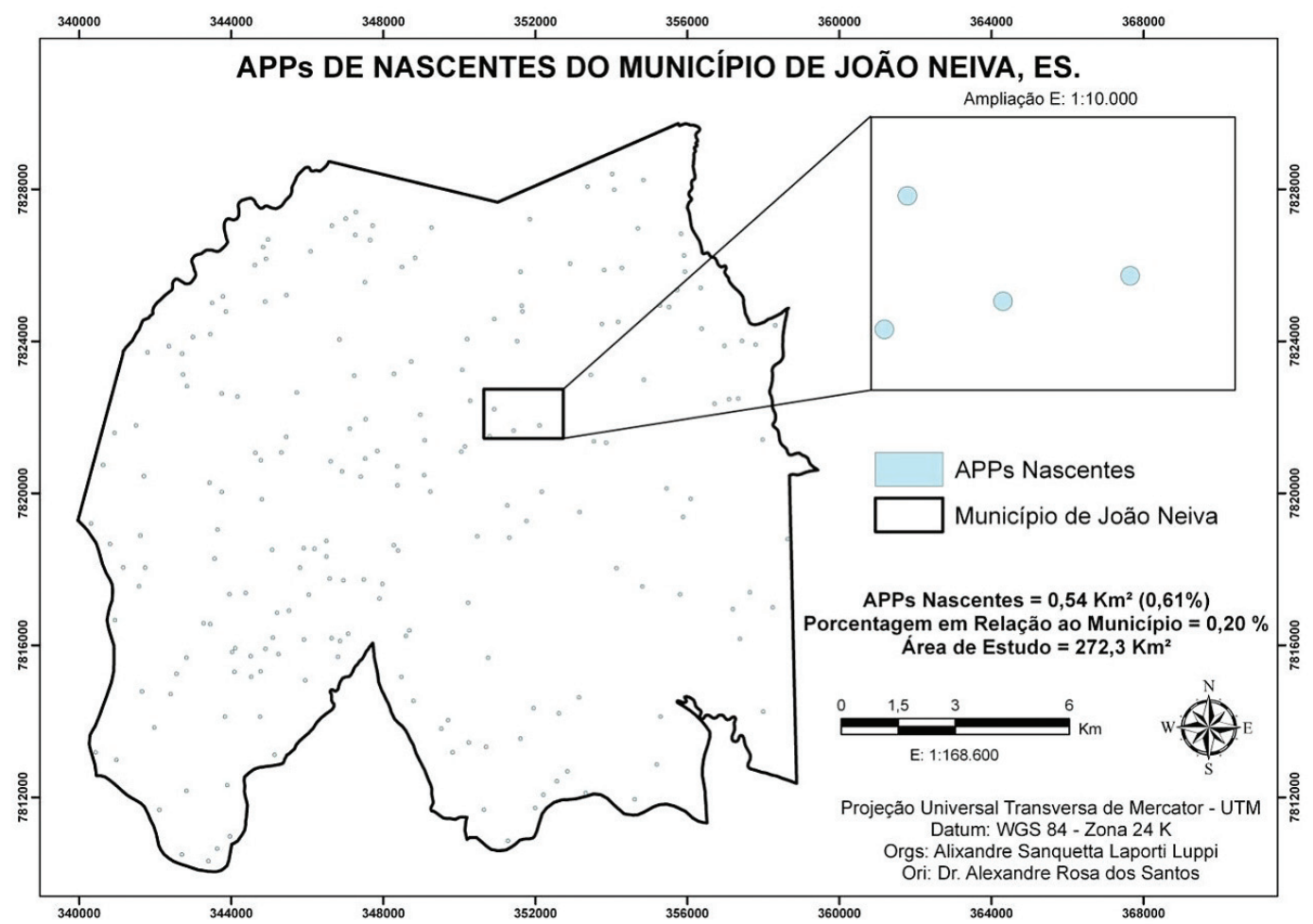

Figura 3. Total das APPs de nascentes do município de João Neiva, ES.

Figure 3. Total of APPs of Spring of the Municipal district João Neiva, ES. 
sedimentos, nutrientes e produtos químicos provenientes das partes mais altas do terreno (Eugenio et al., 2011), os quais afetam a qualidade da água, diminuem a vida útil dos reservatórios, das instalações hidroelétricas e dos sistemas de irrigação. A área ocupada pelas APPs de cursos d'água representa $8,63 \%$ de todo o município, totalizando $23,50 \mathrm{~km}^{2}$. Suas delimitações são mostradas na Figura 4.

O município de João Neiva possui um território que, devido à sua formação geológica, é modelado em rochas cristalinas sendo, portanto, bastante acidentado e elevado: as suas altitudes variam de 60 a 1.090 metros. As áreas ocupadas pelas APPs de declividade abrangem $0,70 \%$ de todo o município, totalizando $1,92 \mathrm{~km}^{2}$. Suas delimitações são mostradas na Figura 5.

Devido ao seu relevo acidentado, o município de João Neiva possui uma extensa área ocupada pelas APPs de topo de morro. Verifica-se a importância de tais áreas serem protegidas, uma vez que, sendo instrumentos de relevante interesse ambiental, elas integram o desenvolvimento sustentável do município, visando gerações futuras.
A área ocupada por essas APPs é de $62,66 \mathrm{~km}^{2}, \mathrm{o}$ que representa $23,01 \%$ da área total do município. As delimitações dessas áreas são mostradas na Figura 6.

A metodologia de delimitação automática das APPs, tendo como referência legal a Resolução n. 303/2002 do Conama (Brasil, 2002), possibilitou identificar e quantificar as categorias de APPs situadas no terço superior dos morros, nas nascentes e respectivas áreas de contribuição, ao longo das margens, cursos d'água e nas encostas com declividade superior a 45 graus (Figura 7 e Tabela 1). Os resultados mostram que a menor e a maior participação entre as categorias de APPs corresponderam, respectivamente, às APPs de nascentes e APPs de topo de morro, com 0,54 km² $(0,20 \%)$ e $62,66 \mathrm{~km}^{2}(23,01 \%)$.

Nota-se ainda que as APPs ocuparam uma área total de $88,64 \mathrm{~km}^{2}$, de um total de $272,30 \mathrm{~km}^{2}$ da área do município, representando $32,55 \%$ de áreas legalmente protegidas.

Adotando metodologia semelhante, Eugenio et al. (2011) verificaram que no município de Alegre 43,50\% do território encontrava-se em APPs, indo ao encontro

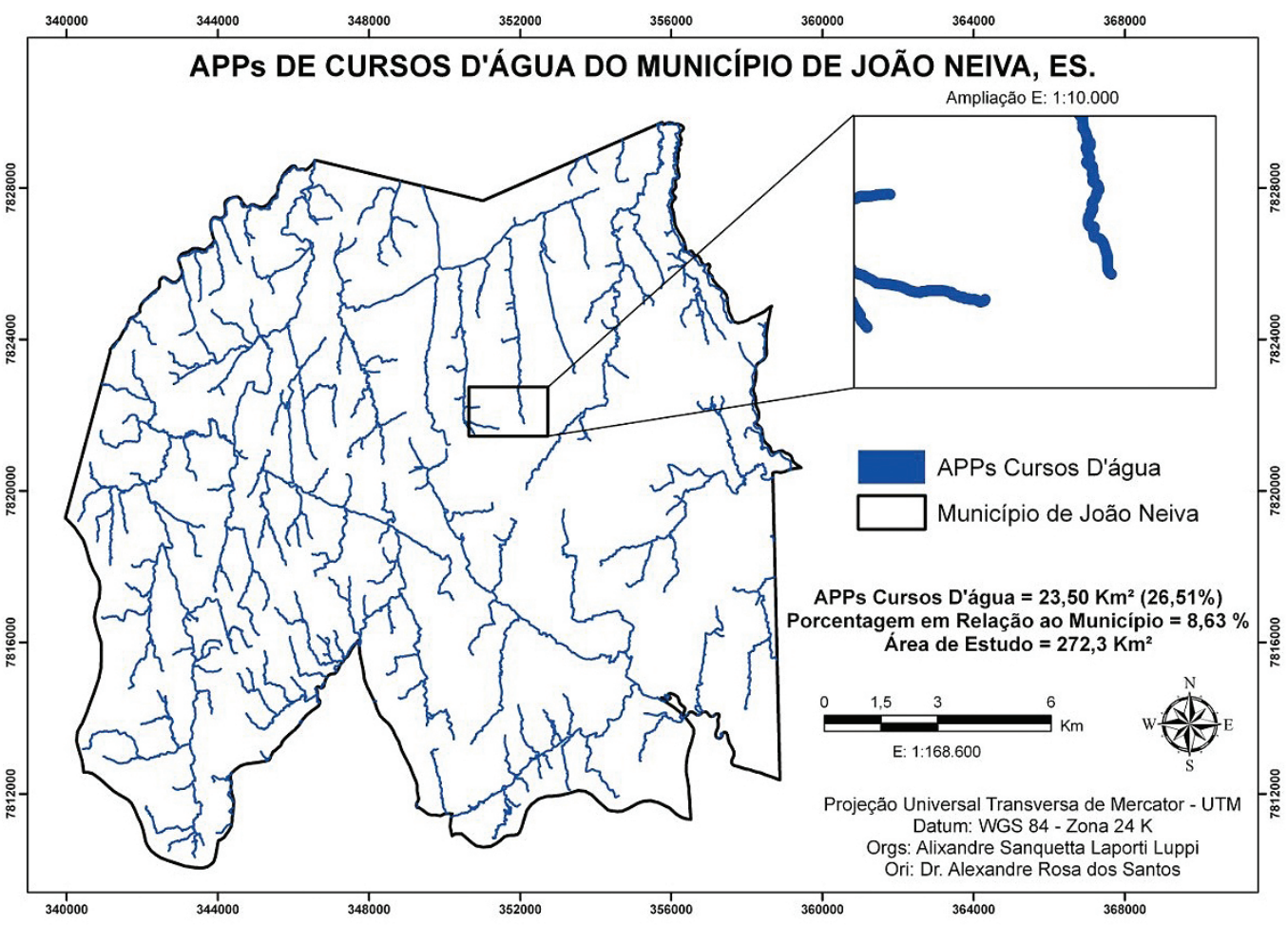

Figura 4. Total das APPs de cursos d'água do município de João Neiva, ES.

Figure 4. Total of APPs of courses of water of the municipal district João Neiva, ES. 


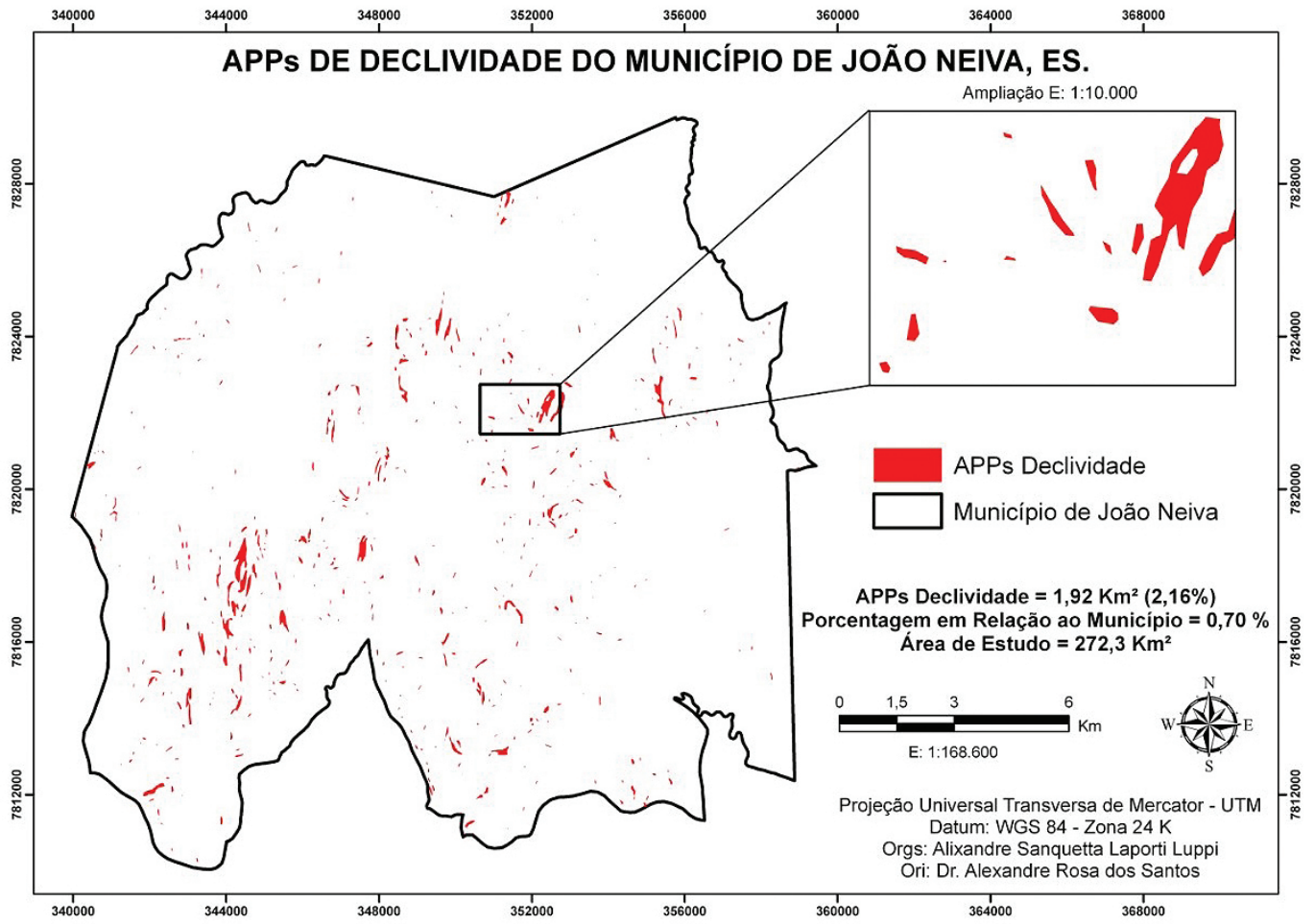

Figura 5. Total das APPs de declividade do Município de João Neiva, ES.

Figure 5. Total of APPs of steepness of the Municipal district João Neiva, ES.

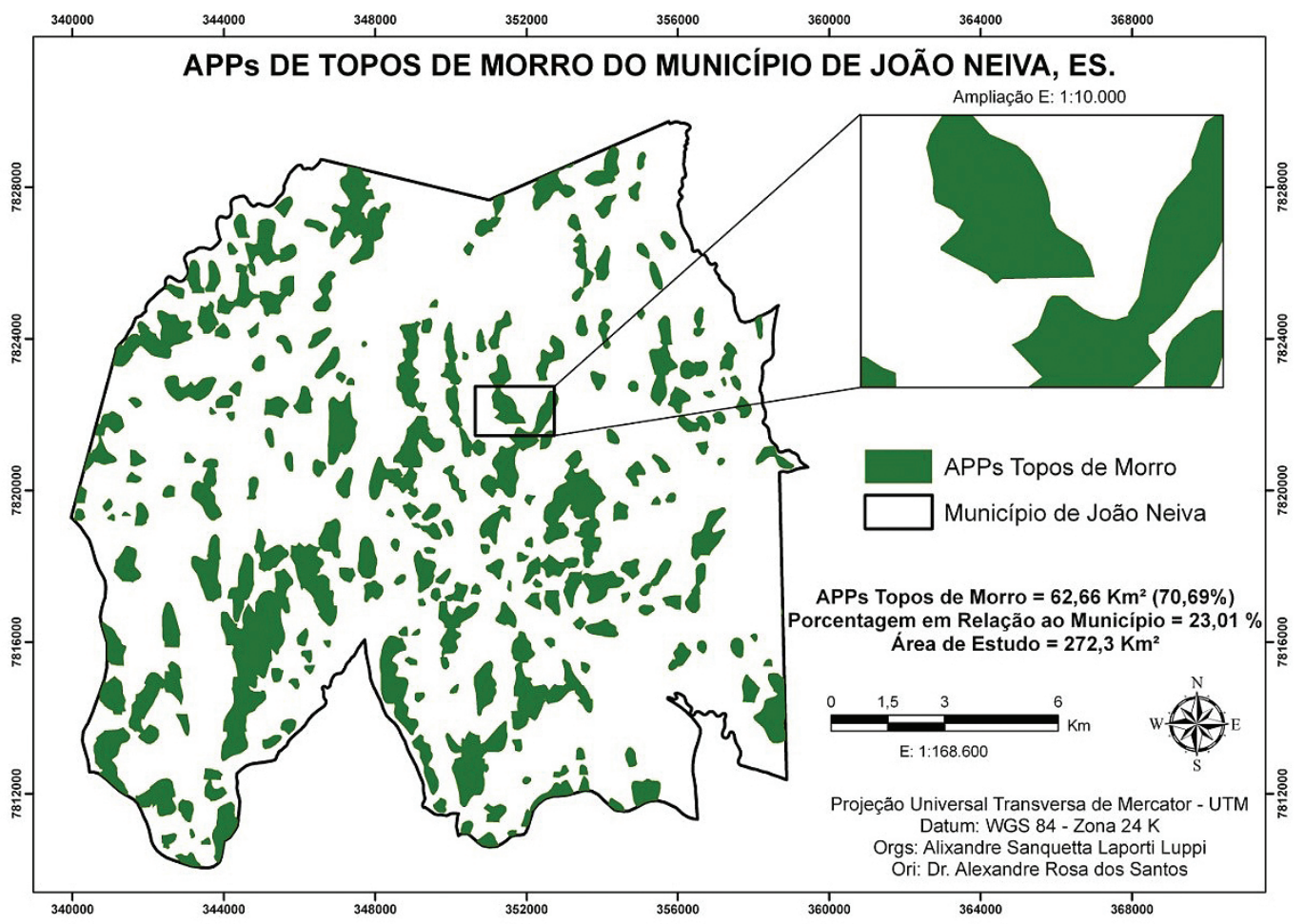

Figura 6. Total das APPs de topo de morro do município de João Neiva, ES.

Figure 6. Total of APPs of hill top of the Municipal district João Neiva, ES. 


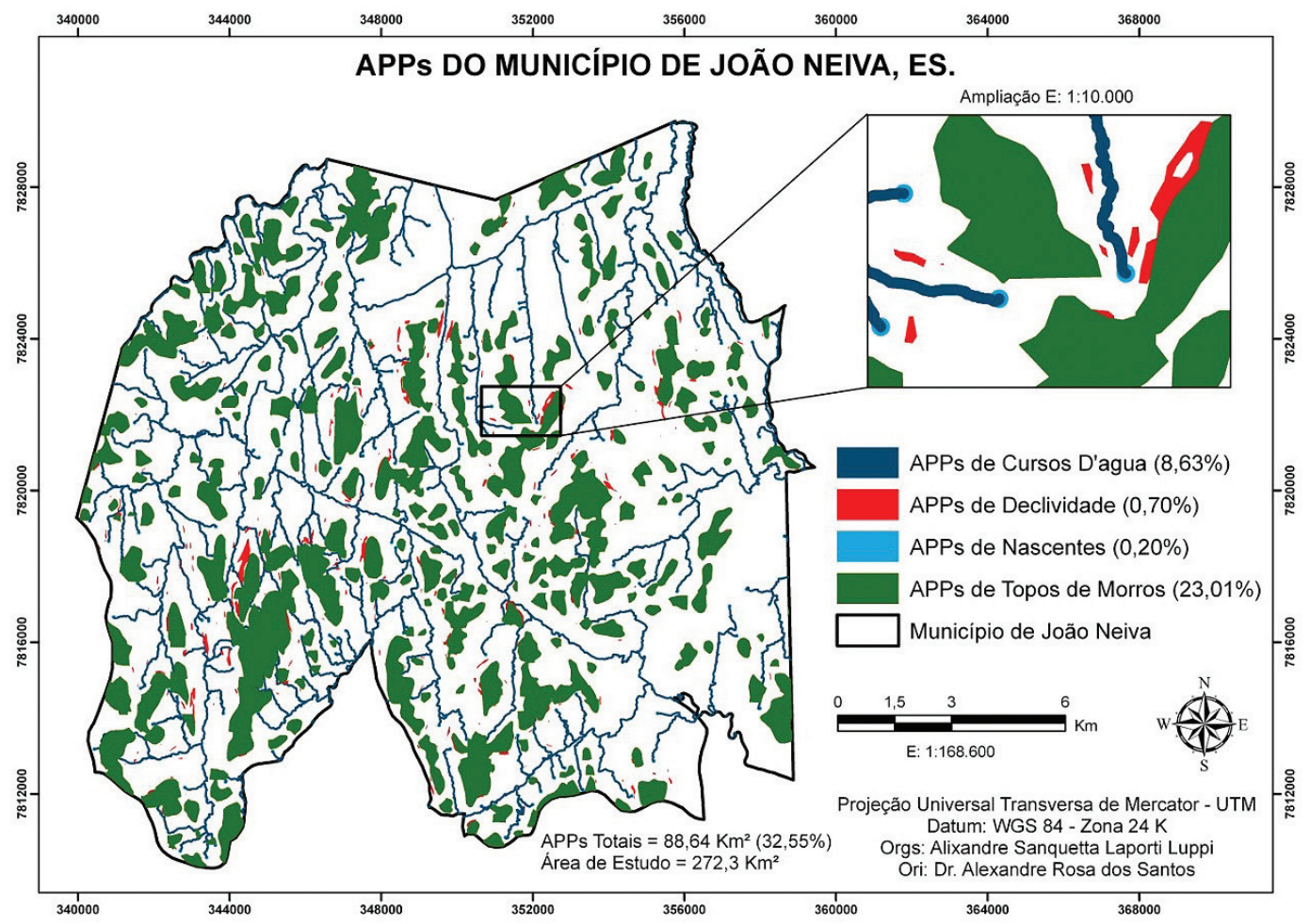

Figura 7. Total das APPs do município de João Neiva, ES.

Figure 7. Total of the APPs of the Municipal district João Neiva, ES.

Tabela 1. Porcentagem das áreas ocupadas pelas APPs no município de João Neiva, ES.

Table 1. Percentage of the busy areas for PPAs in the municipal district of João Neiva.

\begin{tabular}{llccc}
\multicolumn{1}{c}{ APPs } & \multicolumn{1}{c}{ Característica } & Área $\left(\mathbf{k m}^{\mathbf{2}}\right)$ & $\begin{array}{c}\% \\
\text { da área em relação à } \\
\text { área total de APP }\end{array}$ & $\begin{array}{c}\% \\
\text { da área em relação à } \\
\text { área de estudo }\end{array}$ \\
\hline Nascentes & Raio de $50 \mathrm{~m}$ & 0,54 & 0,61 & 0,20 \\
Cursos d'água & Buffer de $30 \mathrm{~m}$ & 23,50 & 26,51 & 8,63 \\
Declividade & Acima de $45^{\circ}$ & 1,92 & 2,16 & 0,70 \\
Topos de morro & Terço superior de morro & 62,66 & 70,69 & 23,01 \\
\hline TOTAL & Sem sobreposições & 88,64 & 100 & 32,55 \\
\hline
\end{tabular}

do que foi constatado para o município estudado, João Neiva, no qual foi de 32,55\%. A diferença pode ser explicada pelo tipo de relevo, já que em João Neiva a APP de topo de morro ocupou 23,01\% e em Alegre, $30,69 \%$.

O conflito do uso da terra nas APPs demonstrou a porcentagem de ocorrência de cada classe de uso da terra no interior das APPs da área de estudo (Figura 8 e Tabela 2).

Os resultados mostram que 59,02\% das áreas de APPs são ocupadas por pastagem, evidenciando o não cumprimento da legislação e de resoluções ambientais. Nessas áreas, a maior porcentagem deveria ser de reflorestamento ou floresta nativa.

Eugenio et al. (2010), em estudo realizado na subbacia hidrográfica do rio Alegre, verificaram que 67,82\% das APPs se encontravam com pastagem; esse resultado vai ao encontro do que foi encontrado neste estudo, $59,02 \%$ para pastagens, entretanto no que tange aos fragmentos florestais, o estudo de Eugenio et al. (2010) encontrou 14,39\% das APPs ocupadas por fragmentos florestais, contrastando com os $39,45 \%$ ocupados pelas 


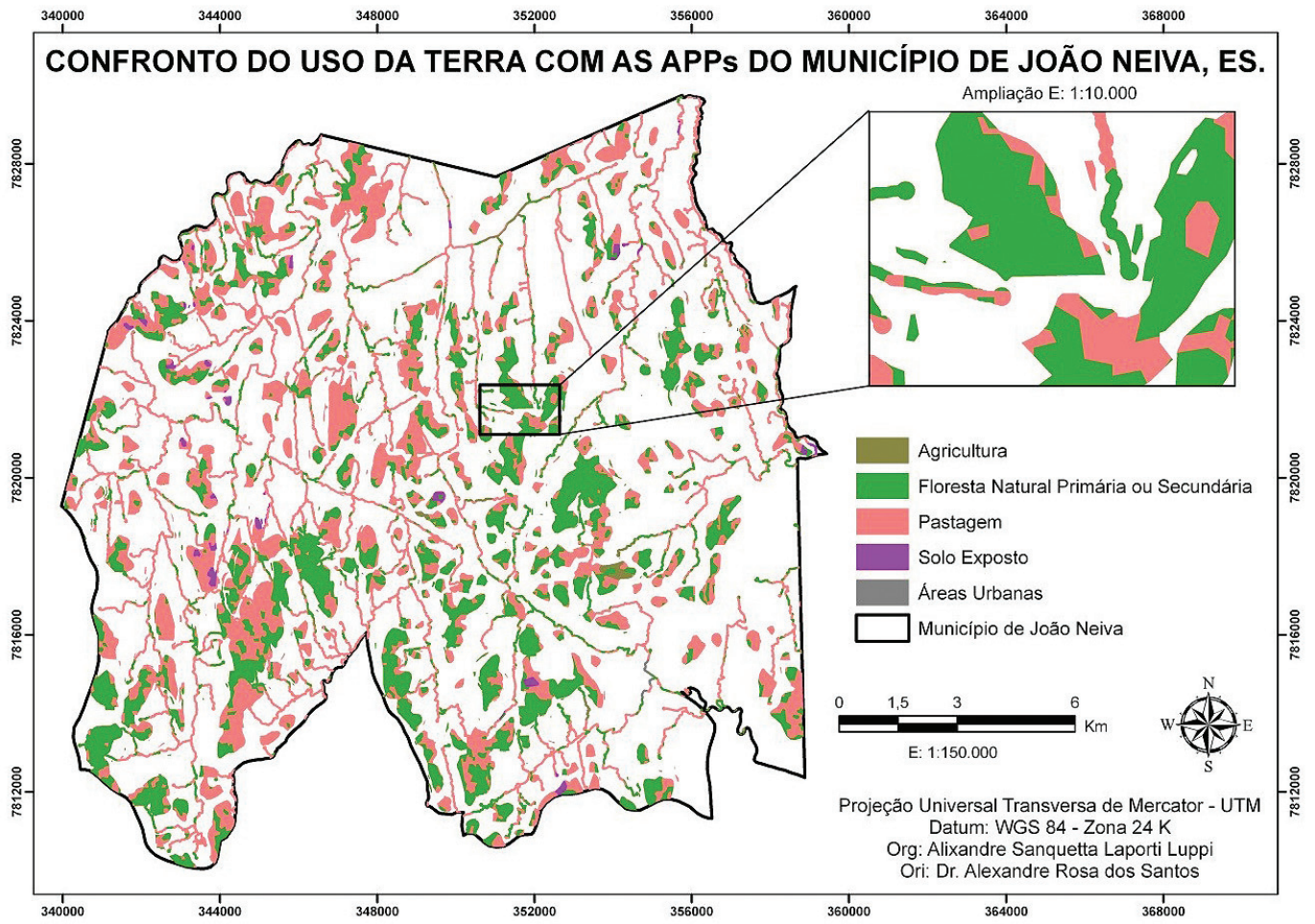

Figura 8. Conflito de uso da terra nas APPs do município de João Neiva, ES.

Figure 8. Clash of land use with the APPs of the municipal district of João Neiva, ES.

Tabela 2. Porcentagem de ocorrência de cada classe de uso da terra no interior das APPs.

Table 2. Percentage occurrence of each class of land use with in the PPAs.

\begin{tabular}{lcc} 
CLASSE & Área $\left.\mathbf{( k m}^{\mathbf{2}}\right)$ & $\begin{array}{c}\% \\
\text { do uso da terra no } \\
\text { interior das APPs }\end{array}$ \\
\hline Solo exposto & 0,77 & 0,87 \\
Agricultura & 0,50 & 0,57 \\
Floresta natural primária ou secundária & 34,85 & 39,45 \\
Pastagem & 52,14 & 59,02 \\
Áreas urbanas & 0,08 & 0,09 \\
TOTAL & 88,64 & 100 \\
\hline
\end{tabular}

florestas primárias e secundárias do presente estudo, ressaltando-se assim que o município de João Neiva, apesar de não estar de acordo com a legislação sobre o uso da terra em APPs, apresenta 40\% das APPs, aproximadamente, com o uso correto da terra.

Nesse contexto, para melhoria da porcentagem supracitada, Louzada (2008) recomenda algumas medidas de controle e prevenção para recuperar as áreas que não estão de acordo com a legislação ambiental:

- A recuperação vegetal com práticas de reflorestamento, o qual pode ser feito pelo plantio de mudas ou ressemeio;
- Fiscalização mais efetiva dos órgãos ambientais, com o intuito de prevenir e multar os possíveis infratores;

- Criação de um sistema que possa fornecer informações relevantes à implantação de projetos de uso e cobertura da terra, proteção e conservação ambiental do município.

\section{CONCLUSÕES}

Considerando as condições e metodologias adotadas no presente estudo foi possível chegar às seguintes conclusões: 
- As APPs ocuparam uma área total de $88,64 \mathrm{~km}^{2}$, de um total de $272,30 \mathrm{~km}^{2}$ da área do município, representando $32,55 \%$ de sua área.

- As APPs de nascentes ocuparam menor área, correspondendo à $0,54 \mathrm{~km}^{2}$, ou seja, $0,20 \%$ da área total do município.

- As APPs de topos de morro ocuparam maior área, correspondendo à $62,66 \mathrm{~km}^{2}$, ou seja, $23,01 \%$ da área total do município.

- Dentro das áreas de APPs, 59,02\% são ocupadas por pastagens, evidenciando o não cumprimento da legislação e das resoluções ambientais.

- A metodologia adotada para delimitação automática das APPs mostrou-se eficaz e rápida, relacionado-as às dimensões do município.

\section{STATUS DA SUBMISSÃO}

Recebido: 18 jul., 2012

Aceito: 25 ago., 2014

\section{AUTOR(ES) PARA CORRESPONDÊNCIA}

\author{
Alixandre Sanquetta Laporti Luppi \\ Centro de Ciências Agrárias - CCA, \\ Universidade Federal do Espírito Santo - UFES, \\ CEP 29500-000, Alegre, ES, Brasil \\ e-mail: alixandregeoinfo@gmail.com
}

\section{REFERÊNCIAS}

Brasil. Conselho Nacional do Meio Ambiente- CONAMA. Resolução Conama n 303, de 20 de março de 2002. Dispõe sobre parâmetros, definições e limites de Áreas de Preservação Permanente. Diário Oficial da República Federativa do Brasil, Brasília, DF, (2002 maio).

Brasil. Lei no 12.651 de 25 de maio de 2012. Dispõe sobre parâmetros, definições e limites de Áreas de Preservação Permanente. Diário Oficial da República Federativa do Brasil, Brasília, DF (2012 maio). [cited 2013 Nov 1]. Available from: http://www.planalto.gov.br/ccivil_03/_Ato20112014/2012/Lei/L12651.htm.

Donadio NMM, Galbiatti JA, Paula RC.Qualidade da água de nascentes com diferentes usos do solo na bacia hidrográfica do córrego rico, São Paulo, Brasil. Engenharia Agrícola 2005; 25:(1).

Espirito Santo. ARES: atlas das áreas com potencial de riscos do Estado do Espírito Santo. Vitória: Imprensa Estadual; 2006. 125 p.
Eugenio FC, Santos AR, Louzada FLRO, Moulin JV. Confronto do uso e cobertura da terra em áreas de preservação permanente da bacia hidrográfica do rio alegre no município de Alegre, Espírito Santo. Engenharia Ambiental 2010; 7: 110-126.

Eugenio FC, Santos AR, Louzada FLRO, Pimentel LB, Moulin JV. Identificação das áreas de preservação permanente no município de Alegre utilizando geotecnologia. Cerne 2011; 17(4): 563-571. http://dx.doi.org/10.1590/S010477602011000400016.

García MJL, Camarasa AM. Use of geomorphological units to improve drainage network extraction from DEM: comparision between automated extraction and photointerpretation methods in the Carraixet catchment (Valencia, Spain). International Journal of Applied Earth Observation and Geoinformation 1999; 1(3-4): 187-195. http://dx.doi.org/10.1016/S03032434(99)85012-0.

Hott MC, Guimarães M, Miranda EE. Método para a determinação automática de áreas de preservação permanente em topos de Morros para o Estado de São Paulo, com base em geoprocessamento. Campinas: Embrapa Monitoramento por Satélites; 2004. 32 p. Documentos n. 34.

Louzada FLRO, Santos AR, Marinho CC, Satler MA. Delimitação automática das áreas de preservação permanentes da bacia hidrográfica do ribeirão Estrela do Norte, ES. In: Anais do IX Encontro Latino Americano de Pós-Graduação - EPG. Ciência e Tecnologia: o paradigma do século XXI; 2009; São José dos Campos, SP. São José dos Campos: UNIVAP; 2009a.

Louzada FLRO, Vieira MVM, Peluzio TMO, Saito NS, Souza SM, Santos AR. Uso de geotecnologia na determinação de áreas de preservação permanente em topos de morros na micro-região de planejamento da Central Serrana, ES. In: Anais do IX Encontro Latino Americano de PósGraduação - EPG. Ciência e Tecnologia: o paradigma do século XXI; 2009; São José dos Campos, SP. São José dos Campos: UNIVAP; $2009 \mathrm{~b}$.

Louzada FLRO. Análise das áreas de preservação permanente da bacia hidrográfica do ribeirão Estrela do Norte - ES [monografia]. Alegre: Faculdade de Filosofia Ciências e Letras de Alegre; 2008.

Oliveira MJ. Proposta metodológica para delimitação automática de áreas de preservação permanente em topos de morro e em linha de cumeada [dissertação]. Viçosa: Universidade Federal de Viçosa; 2002.

Tribe A. Automated recognition of valley lines and drainage networks from grid digital elevation models: a review and a new method. Journal of Hidrology 1992; 139(1-4): 263-293. http://dx.doi.org/10.1016/00221694(92)90206-B. 